\title{
A violência doméstica e os desafios da compreensão interdisciplinar ${ }^{1}$
}

\author{
Domestic violence and the interdisciplinary \\ comprehension challenge
}

\author{
Anamaria Silva NEVES \\ Geraldo ROMANELLI ${ }^{3}$
}

\section{Resumo}

O presente artigo pretende tecer uma reflexão teórica acerca da temática família, especificamente a família que apresenta a violência doméstica, com a violência física de pais e mães contra filhos. Apoiamo-nos na leitura psicodinâmica e em conceitos da Antropologia para a compreensão da amplitude que os conceitos família e violência adquirem na análise das organizações familiares. Ao recorrer a áreas distintas do conhecimento, construímos um saber dinâmico, enriquecedor e que amplia o campo de abordagem do objeto de estudo. A interdisciplinaridade edifica um arranjo teórico questionador, complementar e complexo que faz do pesquisador um elo fundamental entre a teoria, a crítica e a análise da pesquisa.

Palavras-chave: interdisciplinaridade; família; violência doméstica.

\begin{abstract}
The present research intends a theoretical reflection about the family theme, specifically in regards to the family in which domestic violence occurs with physical violence of fathers and mothers towards their children. We support our study on the psychodynamic reading and anthropological notions to comprehend the scope of family concepts and violence acquired in the family organizations analysis. Distinct areas of knowledge have composed a dynamic and rich comprehension, which broadens the approach of the object to be studied. Interdisciplinary edifies a theoretic, complementary and complex arrangement that makes the researcher a fundamental link among theory, critic and research analysis.
\end{abstract}

Key words: Interdisciplinarity; family; domestic violence.

As histórias de Graciliano Ramos (2000), escritas no livro de memórias Infância, versam sobre as descobertas do seu mundo infantil. O imaginário e as fantasias imperam sobre a realidade hostil de um mundo misterioso e excludente. As dolorosas vivências do autor revelam não somente o espaço individual e subjetivo da infância: submergimos nas profundezas da organização familiar representada com maestria pelo

\section{$\boldsymbol{\nabla} \mathbf{\nabla} \boldsymbol{\nabla}$}

- Artigo elaborado a partir da tese de A.S. NEVES, intitulada "A violência física de pais e mães contra filhos: cenário, história e subjetividades". Universidade de São Paulo, 2005.

2 Professora Doutora, Instituto de Psicologia, Universidade Federal de Uberlândia. Av. Pará, 1720, Bloco 2C, Campus Umuarama, 38400-920, Uberlândia, MG, Brasil. Correspondência para/Correspondence to: A.S. NEVES. E-mail: <anamaria@umuarama.ufu.br>.

3 Professor Doutor, Faculdade de Filosofia Ciências e Letras, Departamento de Psicologia e Educação, Universidade de São Paulo. Ribeirão Preto, SP, Brasil. 
autor ao caracterizar os personagens, as cenas e os afetos circundantes. Partimos da escrita refinada e essencialmente humana de Graciliano para caminharmos pelo mundo científico que teoriza a família e suas estratégias de organização.

O literário abre-alas das versões de sofrimento e de angústia da infância serve como inspiração para as histórias ouvidas e interpretadas neste estudo. Histórias singulares mas que refletem fenômenos da subjetividade, comuns ao desenvolvimento humano e à organização familiar. A família é o cenário das versões controversas sobre amor e agressão, confiança e abuso, respeito e invasão, legitimadas em histórias de vida protagonizadas por personagens oriundos das camadas populares da sociedade ao longo das gerações. As histórias das famílias apelam para as reminiscências das dores sentidas, e as lembranças evocadas não se limitam às interlocuções do sujeito consigo mesmo, mas incluem as versões compostas pelas gerações que o antecederam.

A Antropologia, que propõe"o estudo do homem inteiro", leva em consideração as diferentes dimensões do ser humano que vive em sociedade, é "a ciência do homem por excelência e envolve a todos nós" (Laplantine, 1988, p.33).

A reflexão do homem sobre o homem, a natureza que o cerca e a sociedade da qual ele faz parte são antigas, mas apenas no final do século XVIII, segundo Laplantine (1988), um saber científico começa a despontar, fundando a "ciência do homem", a Antropologia. O homem passa a ser objeto de conhecimento, e o "espírito científico" antes aplicado pela Física ou pela Biologia passa a ser aplicado ao próprio homem. O homem, sujeito que se apropria do conhecimento, passa a ser objeto de estudo da ciência.

O autor distingue cinco áreas principais da Antropologia, que, apesar de distintas, mantêm estreita relação entre si: a Antropologia Biológica, a Antropologia Pré-histórica, a Antropologia Lingüística, a Antropologia Social e Cultural (ou Etnologia) e a Antropologia Psicológica. Essa última com ênfase na compreensão dos comportamentos conscientes e inconscientes do ser humano com vistas à apreensão da totalidade do sujeito, confirmando que a dimensão psicológica permanece indissociável do campo de estudo da Antropologia.
A Psicanálise, com Freud, descobre o inconsciente como expressão manifesta do pathos, e assim ela nasce e se desenvolve a partir da investigação do psiquismo e inerente à noção de Psicopatologia. 0 fenômeno do sofrimento humano, sob a perspectiva do sofrimento psíquico, alicerça-se na Psicopatologia Fundamental, termo criado há mais de vinte anos pelo psicanalista francês Pierre Fédida. Em contraste com a Psicopatologia Geral, a Psicopatologia Fundamental se interessa pelo sofrimento singular e pela forma como ele se apresenta constituindo um sujeito - assujeitado pelo pathos. Pathos, que além de significar sofrimento, origina ainda as palavras paixão e passividade. O pathos passa pelo corpo mas vem de fora, fazendo-o padecer (Berlinck, 2000).

O desafio do estudo interdisciplinar que ora se apresenta inclui a compreensão dos aspectos sociais e a produção de subjetividade dos sujeitos, das famílias e das diferentes gerações das famílias que convivem com a violência doméstica praticada por pais e mães contra seus filhos. Séve (1989, p.448) relembra um trecho de Marx, extraído de Correspondance:"a história social dos homens nunca é senão a história de seu desenvolvimento individual". Segundo Séve, as inquietações que movem a ciência, a pesquisa e os confrontos teóricos têm aproximado a Psicanálise dos preceitos marxistas e, nesse sentido, acoplamos ao discurso marxista a fala freudiana de 1921, do texto Psicologia de Grupo e a Análise do Ego, que afirma:"temos que concluir que a psicologia dos grupos é a mais antiga psicologia humana" (Freud, 1976, p.156). Marx que pensa o indivíduo e Freud que assimila o grupo. Pretensões visíveis e anseios inerentes ao entendimento clínico e comunitário permitem transparecer o quanto a interdisciplinaridade é fonte de pesquisa inerente ao conhecimento produzido nas ciências humanas.

\section{Família: conceitos e arranjos}

Muitas vezes pressenti, em minhas insônias do mundo inteiro, que eu também arrasto a condenação daquela casa mítica num mundo feliz onde morríamos todas as noites. G.G. Márquez. Viver para contar.

Na autobiografia do escritor colombiano Gabriel García Márquez, de 75 anos, a casa referida é aquela na qual ele passou a sua infância com a avó, as tias religiosas 
e os homens contadores de histórias de guerra, casa onde cada santo tinha um quarto e cada quarto tinha um morto. Os cenários que acolhem os diferentes modelos familiares e que arrastam infinitas histórias e dramas na vida dos sujeitos de toda a humanidade refletem as características oscilantes que a família engloba.

A exemplo do que vinha ocorrendo na década de 1970, as décadas de 1980 e 1990 foram marcadas pela redução relativa do modelo tradicional de família nuclear (constituída por marido, esposa e filhos) e pelo aumento proporcional do número de famílias chefiadas por mulheres e por unidades domésticas unipessoais. A evolução dos diferentes tipos de unidades domésticas mostra a significativa redução do tamanho das famílias, com número médio menor de pessoas e de filhos (IBGE, 2001).

As relações atualmente conhecidas que unem rede de parentesco, unidade doméstica/residencial e grupo conjugal tiveram estruturas diferenciadas nas diversas sociedades e em momentos históricos específicos (Bruschini, 1997), confirmando que a mutabilidade e a não-naturalidade são especificidades do estudo da família.

A família é uma unidade dinâmica, um grupo social, um espaço de convivência fundamental ao desenvolvimento dos seus membros; contudo possui características e funções próprias, que são historicamente questionadas e redefinidas. A família não comporta uma definição unívoca, primordialmente centrada em parâmetros excludentes. É justamente o saber produzido por diversas disciplinas que auxilia a pensar o conceito e o significado contextualizado do substantivo família.

A família é um grupo primordial no âmbito do desenvolvimento de sujeitos psíquicos singulares, bem como na formação ideológica dos cidadãos que a compõem. Ideologia que, de acordo com Guareschi (1999), tanto serve para sustentar relações justas e éticas como serve para alimentar relações assimétricas, de dominação.

A amplitude do conceito de família nos impele à busca de recortes que delimitem os horizontes de discussão. A definição de Osório (1996, p.16) clareia e, concomitantemente, apresenta elementos introdutórios sobre as variáveis que envolvem a conceituação:
Família é a unidade grupal onde se desenvolvem três tipos de relações pessoais-aliança (casal), filiação (pais/filhos) e consangüinidade (irmãos) - e que, a partir dos objetivos genéricos de preservar a espécie, nutrir e proteger a descendência e fornecer-lhe condições para a aquisição de suas identidades pessoais, desenvolveu através dos tempos funções diversificadas de transmissão de valores éticos, estéticos, religiosos e culturais.

A origem etimológica da palavra família denota conotações instigantes quanto às suas derivações sociais. Família, do vocábulo latino famulus, significa servo ou escravo, do que se entende que primitivamente a família era considerada um conjunto de servos ou criados de uma pessoa. Dessa forma, as origens do termo traduzem as origens da tipologia relacional estabelecida, ou, como Osório (1996) repara, a raiz etimológica refere-se à natureza possessiva dos vínculos familiares entre os povos primitivos. O autor considera que as concepções de poder e posse estão vinculadas às origens da família e à sua constituição grupal.

Lasch (1991), em seu livro Refúgio num mundo sem coração, tenta recuperar os percalços da família no último século. O autor pontua que, com a selvageria crescente do mundo dos negócios e da política, o homem procura refúgio na família; entretanto ela aparece gradativamente mais frágil e incapaz de acolher esse sujeito carente. Afirma que a família contemporânea é produto da ação humana e do controle social e não de forças sociais abstratas. Lasch fala sobre a sociedade moderna e o controle social antes relegado às famílias ou aos indivíduos, afirmando que o Estado controla o corpo, o espírito e a vida privada dos sujeitos. Se alguns críticos apontaram Lasch como um admirador da família burguesa ou um nostálgico defensor da família patriarcal, entendemos que o autor imprime o diálogo crítico com a Antropologia, a Psicanálise e a Sociologia e, sem recorrer a versões ortodoxas sobre as relações familiares, promove um debate instigante, apontando a família como agente de socialização que reproduz padrões culturais no indivíduo.

Bourdieu (1996) apresenta a família como principal sujeito das estratégias de reprodução, não apenas biológica, mas reprodução das relações sociais. O autor diz que a família é produto do trabalho de instituição que tem como objetivo instituir, de forma adequada e 
duradoura, em seus membros, sentimentos que assegurem a integração, condição de perpetuar a unidade familiar. A família precisa se afirmar como corpo que luta para existir mediante relações de força econômica e simbólica.

Se Lasch resgata aspectos catastróficos e pouco otimistas da família, com foco na família norte-americana, Bourdieu especifica ainda características de existência e estruturação da família atual. Romanelli (2003) retoma Bourdieu e acrescenta que na análise de estratégias é importante criar a dimensão da temporalidade, já que os integrantes da família percorrem as trajetórias de vida de forma diversa dos demais. A partir daí, a análise do ciclo de vida familiar permite acompanhar o movimento dos membros da família e as posições sociais que são ocupadas nesse processo.

A discussão aponta para a família como uma construção social, um grupo ativo na formação e transformação dos padrões culturais e afetivos. Biasoli-Alves e Simionato-Tozo (1998) ressaltam que a família, seja como conceito, seja como grupo primário, apresenta alterações ao longo dos diferentes momentos históricos e nas diversas culturas em que está inserida. A família, ao ser transformada, assimila, modifica e devolve à sociedade os elementos processados em seu interior que, por sua vez, os modifica. A diversidade dos arranjos familiares descritos nas diferentes culturas e em distintos períodos nos permite observar a importância da família na orientação dos filhos, em particular.

Na busca por definições de família, alguns autores recorrem ainda aos conteúdos míticos como referência primária. Osório (1996), focalizando a antropogênese, afirma que as mitologias, ao criar o homem, situam-no em condição relacional no seio familiar e, nesse sentido, resgata a versão mitológica greco-romana da criação do universo e dos seus habitantes.

A versão bíblica, com Eva e Adão e a expulsão do paraíso, representa, simbolicamente, o repúdio do pai aos filhos. Os irmãos Caim e Abel espelham a rivalidade entre os irmãos. O mito de Édipo, que envolve a punição, a culpa, o desejo e o emaranhado afetivo, amplia a compreensão do ciclo afetivo da vida familiar. As propriedades da família conferem-lhe, mitologicamente, a condição de reduto do nascimento do relacionamento humano. Relação que, de acordo com Guareschi (1999), é definida pela existência das pessoas em relação a outras, ordenação que se faz intrínseca, ou, em latim, ordo ad aliquid. A família, originária das relações humanas, é entendida como grupo primordial.

Familiar, familiarizado, em família, da família e de família são conotações dispersas de um lugar simbolicamente definido, um reduto onde se encenam romances trágicos, dramáticos, aventureiros, felizes e contraditórios, com personagens amados e odiados, simultaneamente, no reduto do composto familiar. Se a família se constitui uma representação, é também um grupo de convivência que se organiza de acordo com diferentes arranjos e se apresenta em distintas versões. Faz-se mister a evocação dos cenários que não apenas a historicizam, mas que a compõem: a casa, a domesticidade, a intimidade e a produção da violência doméstica nessa conjunção.

\section{Violência doméstica: o desafio da compreensão}

Pensar a violência implica considerar as bases e o desenvolvimento histórico que determinam as formas que ela assume ao longo da organização das sociedades. Raggio (1992), psicanalista, propõe "concentrar nossa atenção no bosque antes que nas folhas" (p.26). O autor explica que o ser humano necessita da agressividade para viver, mas a violência institucional e sistemática é um fenômeno que nasce com as sociedades de classe e penetra no processo de exploração do homem pelo homem por meio de mecanismos de repressão. Raggio argumenta que a ordem capitalista reproduz a violência assim como reproduz o capital e, para isso, reproduz sujeitos ideologicamente violentos que, por fim, produzem e consomem a violência.

As raízes histórico-sociais da violência, o bosque, e o inconsciente individual, as folhas, formado por fantasias edípicas, desejos e alicerçado por um superego de características variantes são processos inerentes ao sujeito social. A análise do sujeito e a análise da família consistem em inserirmos a discussão do homem como um sujeito em que a história e a violência imprimiram suas marcas.

A prerrogativa de que o tema violência doméstica está relacionado à violência geral que impera na 
nossa sociedade foi um dos eixos principais na determinação da condução teórica a ser seguida. A pesquisa bibliográfica demonstrou como a questão da violência se faz presente nas variadas áreas do conhecimento - História, Sociologia, Antropologia, Economia, Psicologia - e, via de regra, sustenta propostas plausíveis que norteiam as discussões e embasam definições e reflexões sobre a especificidade da violência doméstica.

Enfatizemos a agressão. A palavra agreddi, de origem latina, significa abordar, avançar e, nesse sentido, o oposto da agressão não é paz ou amizade, mas o isolamento ou inexistência de qualquer tipo de contato. Segundo May (1972), quando a capacidade de se colocar no mundo diante do outro, de reivindicar posições, direitos - a exemplo do que ocorre com as minorias - e todas as formas de expressão se tornam inoperantes, a agressão emerge como forma de reação. O autor postula que há dois tipos básicos de agressão: a destrutiva e a construtiva. Ao explanar acerca da segunda, retoma as histórias de homens públicos para enfocar formas de direcionar aspectos agressivos do ser em prol de causas nobres como o abolicionismo. É importante frisar que a agressão construtiva inclui o confronto com o outro sem causar-lhe dano. Anthony Storr, citado por May (1972), compara o ato de lutar e o ato de fazer amor nos humanos e pontua que as brigas entre amantes terminam, com freqüência, em relações sexuais, com uma estranha relação entre combatente e amante como componentes de uma mesma fábula. Para May é fundamental reiterar aspectos positivos da agressão e considerar que os aspectos negativos são expostos em demasia por causa da culpa e da ansiedade incrustadas nos ataques movidos contra o outro. $\mathrm{O}$ autor conclui que as atividades humanas mesclam formas positivas e negativas de agressão.

Quando a agressão se torna ineficaz, impera a violência, como explosão primária predominantemente física. A violência seria um caminho de descarga tensional na busca por um senso de significação do sujeito. Segundo Gerald Chrzanowski, citado por May (1972), a agressão está associada a um objeto ao qual é direcionada a fúria, por assim dizer. Na violência, a relação com o objeto é danificada.

A maneira como o sujeito é capaz de interpretar o mundo à sua volta parece decisiva na disposição para rivalizar com o outro. A violência seria, assim,
... uma organização dos poderes da pessoa a fim de provar o seu próprio poder, a fim de estabelecer o valor do eu ... mas ao unir os diferentes elementos do eu, omite a racionalidade (May, 1972, p.153).

O autor segue dizendo que violência e comunicação são excludentes e que quando uma pessoa tem um acesso de cólera a capacidade de fala é bloqueada e a energia é transferida para os músculos, no preparo primitivo para o ataque e a luta. Significa que foram desfeitas e desorganizadas as possibilidades de comunicação e entram em cena a agressão e a violência. A linguagem, quando utilizada para despertar emoções de origem agressiva das pessoas, pode ser tão violenta quanto a força física, de forma que a incapacidade de comunicar-se denuncia a deterioração dos vínculos entre as pessoas.

O tema dos maus tratos contra crianças e adolescentes, como uma questão social, é recente e atravessou diferentes níveis no último século. Apesar do progresso gradativo no estudo da violência ou maus tratos contra a criança, algumas questões permanecem. Explosões emocionais contra os que estão mais próximos e mais indefesos definem a síndrome do pequeno poder, em que o mais forte exerce o seu pequeno poder sobre um mais fraco (Guerra, 1998). A autora descreve como a violência doméstica, como violência intersubjetiva, consiste na violência interpessoal, com abuso do poder disciplinador, ocasionando um processo de vitimização e imposição de maus tratos.

Na cena da violência doméstica existem três formas de desempenhar o papel no enredo familiar: como vítima, ator e/ou testemunha (Koller, 2000). O autor da infração, o sujeito que transgride não somente as normas sociais mas invade a intimidade e a organização afetiva e corpórea do outro, utiliza-se da persuasão e do controle para manter o outro na condição de dominado e subjugado. O desafio é que a violência doméstica nem sempre é claramente identificável e a vítima, inerte, assujeitada, sofre mas tem dificuldade de encontrar alternativas de ajuda, seja pela ameaça sofrida, seja pela ausência de elementos norteadores de auxílio, como a escola, a creche e os vizinhos, no caso de crianças vitimizadas.

Belsky e Vondra (1989), em estudos sobre a etiologia dos maus tratos praticados por pais e mães contra as suas crianças, propõem um modelo de estudo 
sobre os determinantes parentais, ou seja, eles criticam os modelos psiquiátricos e aqueles exclusivamente fundados em explicações do ambiente e sugerem um modelo geral dos determinantes do funcionamento parental. Sob essa perspectiva são consideradas as características individuais dos pais, das mães e dos filhos (personalidade parental e características das crianças), características sociais (o contexto que envolve as relações conjugais, a rede social, o trabalho), e, por fim, fatores circunstanciais (a pobreza, descontentamento com o emprego, ignorância sobre o desenvolvimento infantil). Cada elemento citado deve ser analisado com igualdade de prevalência, o que significa que para cada caso devem ser avaliados os elementos e as características que apresentam na família estudada.

Bringiotti (2000) postula que as definições sobre maus tratos infantis devem englobar tanto aspectos teóricos, como uma definição operacional, com vistas a facilitar a identificação do fenômeno. A autora seleciona a seguinte definição de maus tratos infantis:

Qualquer dano físico ou psicológico não acidental contra uma criança menor de dezesseis ou dezoito anos - segundo o regime de cada país - praticado por seus pais ou cuidadores e que ocorre como resultado de ações físicas, sexuais ou emocionais de omissão ou comissão e que ameaçam o desenvolvimento normal tanto físico quanto psicológico da criança (Bringiotti, 2000 apud Fuster e Ochoa, 1993, p.35, tradução nossa). doméstica:

Guerra (1998) diferencia quatro tipos de violência

a) Violência sexual: envolve atos hetero ou homossexuais entre o adulto e uma criança ou adolescente e tem por finalidade estimular sexualmente essa criança ou adolescente para obter estimulação sexual para si ou para outrem;

b) Violência psicológica: ocorre nas ocasiões em in que odulto ameaça e deprecia a criança provocando-lhe sofrimento mental;

c) Negligência: representa a falha ou omissão dos pais ou responsáveis em prover as satisfações físicas e emocionais dos filhos, desde que a falha não seja mero resultado das condições de vida que estão fora do seu domínio:

d) Violência física: a autora realiza um apanhado teórico e, em âmbito nacional, oferece um espectro que inclui nomenclaturas como síndrome, violência, abuso-vitimização física.

A afirmação de que o cenário da violência doméstica é um desalento à crença na família que, em quatro paredes, se ama e se respeita não pretende excluir o afeto amoroso e incondicional. A intenção é ainda incluir uma outra realidade vigente nas famílias estudadas: a coexistência de investimento afetivo e a ruptura de vínculos ao longo das gerações.

A violência doméstica aparece em todas as camadas sociais em diferentes momentos históricos, mas nas camadas populares ela se torna pública em virtude da denúncia e do decorrente acompanhamento ou intervenção dos órgãos públicos. As camadas altas da sociedade mantêm o anonimato e compram a discrição através dos atendimentos particulares, quando o fazem.

O tema violência doméstica é contundente em dois âmbitos principais, desde sua definição, em que os limites que vão do tapinha ao espancamento são controversos, até os parâmetros éticos e pedagógicos sobre castigos e punições físicas, que agregam pesquisadores de diferentes influências. Quiçá existam outras formas de se pensar a violência física que incluam ainda o entendimento do uso do corpo, esse corpo violento que usurpa o lugar do outro mas que também tenta se aproximar do outro, marcar o outro e não apenas machucá-lo.

A interdisciplinaridade é buscada no sentido de revisitar as abrangências que delineiam a violência física sem a frenética compulsão da categorização do tipo de violência ou do atendimento à denúncia registrada nos prontuários das instituições de atenção à infância. Fica premente a reflexão sobre as estratégias familiares na educação dos filhos, estratégias que incluem há séculos a punição física. O olhar se ajusta sobre a família agressora denunciada que recebe atenção e análise sem rotulações reducionistas.

A interdisciplinaridade nos apresenta uma nova relação com o conhecimento e a construção coletiva do saber (Fazenda, 1998). Por disciplina, entende-se um ramo do saber, do conhecimento, que também está imerso numa noção de conduta, valores, de relacionamentos. Conforme Etges (1995), a verdadeira interdisciplinaridade possibilita medeia a comunicação entre os cientistas e a partir disso estabelece uma linguagem 
comum entre diferentes campos. Não há o surgimento de uma nova teoria, mas a compreensão do que o outro faz, bem como a descoberta de novas estratégias tanto na própria ciência como na ciência do outro. A interdisciplina-ridade não objetiva unificar as diversas ciências e sim levar à compreensão dessas de uma forma crítica e criativa.

É preciso desconstruir o conceito e pesquisar a família, o que implica questionar fórmulas prontas de análise e descobrir as sutilezas dos discursos dos personagens que compõem os agrupamentos familiares. A atenção e o investimento de pesquisadores sobre as organizações familiares alertam para a prevenção do abandono de crianças, da institucionalização infantil e do rompimento de relações afetivas desgastadas, mas, na maior parte dos episódios verificados, passíveis de serem reconstruídas e trabalhadas.

A Antropologia auxilia a compreender a família não como bem de consumo descartável, reposto por instituições secundárias às quais é delegado o papel da maternagem e educação básica, e sim como instituição primária, incondicionalmente importante na construção de identidades, valores, afetos e cidadania. Marcilio (1997) nos aviva a memória e lembra que o Brasil revela a cruel realidade de ter sido o último país a abandonar as Rodas dos Expostos - dispositivos utilizados no Brasil no período que vai do século XVIII até 1950, com o objetivo caritativo e religioso de abrigar crianças e recém-nascidos abandonados por seus familiares - referendando, na atualidade, a herança impregnada no movimento compulsivo da institucionalização como recurso imediato frente aos desajustes familiares.

Lembremo-nos de autores como Becker (1998), que comenta a tragédia que envolve a ruptura dos vínculos familiares e pondera sobre as alternativas oficiais - como a concessão da guarda, tutela e adoção - como soluções cabíveis mas trágicas na história dos personagens envolvidos. Ou ainda Vicente (1998, p.54), ao postular que a institucionalização infantil tem gerado, historicamente, crianças analfabetas com falta de perspectivas de vida autônoma e independente:

As milhares de famílias sem terra, sem casa, sem trabalho, sem alimento enfrentam situações diárias que ameaçam não só seus corpos - território último do despossuído - mas, simultaneamente, seus vínculos e subjetividades.
Abordar a família, considerando as peculiaridades que o termo pressupõe, significa repensá-la na ordenação do passado, do presente e do futuro, numa perspectiva circular, estrutural, dialeticamente efetivada na relativização de parâmetros ditos universais. Por fim, nosso estudo qualifica a subjetividade e questões de cunho sociocultural e psicanalítico enquanto complementares na compreensão dos romances familiares.

\section{Referências}

Becker, M. J. (1998). A ruptura dos vínculos: quando a tragédia acontece. In S. M. Kaloustian (Org.), Família brasileira: a base de tudo (pp.60-76). São Paulo: Cortez.

Belsky, J., \& Vondra, J. (1999). Lessons from child abuse: the determinants of parenting. In D. Cicchetti \& V. Carlson, (Eds.), Child maltreatment: theory and research on the causes and consequences of child abuse and neglect. New York: Cambridge University.

Berlinck, M. T. (2000). Psicopatologia fundamental. São Paulo: Escuta.

Biasoli-Alves, Z. M. M., \& Simionato-Tozo, S. M. P. (1998). O cotidiano e as relações familiares em duas gerações. Cadernos de Psicologia e Educação Paidéia, 8, 137-149.

Bourdieu, P. (1996). Razões práticas sobre a teoria da ação. Campinas: Papirus.

Bringiotti, M. I. (2000). La escuela ante los niños maltratados (pp.15-76). Buenos Aires: Paidós.

Bruschini, C. (1997). Teoria crítica da família. In M. A. Azevedo \& V. N. A. Guerra (Orgs.), Infância e violência doméstica: fronteiras do conhecimento (2a ed., pp.49-79). São Paulo: Cortez.

Etges, N. G. (1995). Ciência, interdisciplinaridade e educação. In A. P. Jantsch \& L. Bianchetti (Orgs.), Interdisciplinaridade: para além da filosofia do sujeito. Petrópolis: Vozes.

Fazenda, I. C. (1998). Didática einterdisciplinaridade. Campinas: Papirus.

Freud, S. (1976). Psicologia de grupo e análise do ego (pp.139-171). Edição standard brasileira. Rio de Janeiro: Imago.

Guareschi, P. A. (1999). Relações comunitárias: relações de dominação. In R. H. F. Campos (Org.), Psicologia social e comunitária: da solidariedade à autonomia. Petrópolis: Vozes.

Gerra, V. (1998). Violência de pais contra filhos: a tragédia revisitada. São Paulo: Cortez

Instituto Brasileiro de Geografia e Estatística. (2001). Síntese de indicadores sociais. Rio de Janeiro: IBGE.

Koller, S. H. (2000). Violência doméstica: uma visão ecológica. Violência doméstica. Brasília: Unicef. 
Lasch, C. (1991). Refúgio num mundo sem coração. A família: santuário ou instituição sitiada? Rio de Janeiro: Paz e Terra.

Laplantine, F. (1988). O campo e a abordagem antropológicos. Aprender antropologia (pp.13-33). São Paulo: Brasiliense.

Marcilio, M. L. (1997). A roda dos expostos e a criança abandonada na história do Brasil: 1726-1950. In M. C. Freitas (Org.), História social da infância no Brasil. São Paulo: Cortez.

Márquez, G. G. (2003). Viver para contar. São Paulo: Record.

May, R. (1972). Poder e inocência: uma análise das fontes de violência. Rio de Janeiro: Zahar.

Osório, L. C. (1996). Família hoje. Porto Alegre: Artes Médicas.

Raggio, V. (1992). Concepção materialista da história, psicanálise e violência. In R. Amoretti (Org.), Psicanálise e Violência: metapsicologia-clínica-cultura. Petrópolis: Vozes.

Ramos, G. (2000). Infância. São Paulo: Record.

Romanelli, G. (2003). Questões teóricas e metodológicas nas pesquisas sobre família e escola. Itinerários de pesquisa: perspectivas qualitativas em sociologia da educação (pp.245-263). Rio de Janeiro: DP \& A.

Séve, L. (1989). A personalidade em gestação. In P. Silveira \& B. Doray. Elementos para uma teoria marxista da subjetividade. São Paulo: Vértice.

Vicente, C. M. (1998). O direito à convivência familiar e comunitária: uma política de manutenção do vínculo. In S. M. Kaloustian (Org.), Família brasileira: a base de tudo (pp.47-59). São Paulo: Cortez.

Recebido em: 12/9/2005

Versão final reapresentada em: 6/1/2006

Aprovado em: 19/6/2006 